\title{
sciendo
}

\section{ASSOCIATIONS OF CAST, CAPN1 AND MSTN GENES POLYMORPHISM WITH SLAUGHTER VALUE AND BEEF QUALITY - A REVIEW}

\author{
Andrzej Węglarz ${ }^{1 \bullet}$, Anna Balakowska² ${ }^{2}$ Dominika Kułaj ${ }^{3}$, Joanna Makulska ${ }^{1}$ \\ ${ }^{1}$ Department of Animal Genetics, Breeding and Ethology, University of Agriculture in Krakow, \\ Al. Mickiewicza 24/28, 30-059 Kraków, Poland \\ ${ }^{2}$ Technology Transfer Center, University of Agriculture in Krakow, Al. Mickiewicza 21, \\ 31-120 Kraków, Poland \\ ${ }^{3}$ Department of Animal Reproduction, Anatomy and Genomics, University of Agriculture in Krakow, \\ Al. Mickiewicza 24/28, 30-059 Kraków, Poland \\ •Corresponding author: rzweglar@cyfronet.pl
}

\begin{abstract}
The slaughter value of cattle and beef quality are influenced by many factors, which can generally be divided into antemortem (breed, sex, age, housing system, diet, pre-slaughter handling) and postmortem (post-slaughter processing, chilling temperature, packaging). Studies of many authors have shown that meat quality traits can be also influenced by the individual genetic background of an animal. Numerous studies have been conducted worldwide to determine the functions of various genes as well as polymorphisms with potential effects on fattening and slaughter value of cattle and on beef quality. This study reviews the most important research done on the associations of polymorphisms in the calpain, calpastatin and myostatin genes with carcass traits and beef quality. Knowledge about the genes and chromosome regions associated with desired meat quality characteristics may prove very helpful when selecting pairs for mating and estimating the breeding value of offspring, mainly because it is difficult to improve meat quality traits based on conventional selection methods due to their low heritability and polygenic regulation. Furthermore, meat quality evaluation is expensive and can only be carried out after slaughter.
\end{abstract}

Key words: calpain, calpastatin, myostatin, slaughter value, beef

\section{Factors affecting slaughter value and beef quality}

Numerous studies have demonstrated that slaughter value of cattle and beef quality are significantly influenced by many factors, the most important of which include the breed, sex, age, housing system, feeding, pre-slaughter handling, but also the individual genetic background of an animal (Mach et al., 2008; Węglarz, 2011). The impact of breed genotype was reported by many authors, but it is difficult to pinpoint which breed is the most suitable for beef production (Keane et al., 2011; Magolski et al., 2013). Breeds differ in many aspects including degree of muscling, intramus- 
cular fat content, meat aroma, juiciness and tenderness. These originating from Bos taurus exhibit earlier maturation, lower calpastatin activity, smaller percentage of connective tissue. higher meat tenderness and lower cooking loss compared to the breeds derived from Bos indicus (Chávez et al., 2012; Lozano et al., 2016). There are also differences between dairy breeds and beef breeds. For example, Iso-Touru et al. (2018) reported lower meat tenderness in dairy Nordic Red Cattle compared with beef breed (Aberdeen Angus).

\section{Most important beef quality traits}

Beef quality traits of importance for consumers include colour, tenderness, taste and juiciness. A significant role is also played by freshness, low fat content and high nutritive value (Resurreccion, 2004).

Colour depends on the concentration and chemical form of myoglobin found in the muscle tissue. Fresh meat contains deoxymyoglobin (DMb), oxymyoglobin $(\mathrm{OMb})$ and metmyoglobin $(\mathrm{MMb})$. DMb form is responsible for the purplish-red colour of fresh meat. In the presence of oxygen, deoxymyoglobin is oxidized to $\mathrm{OMb}$, resulting in bright pink-red colour. When the above forms are oxidized to $\mathrm{MMb}$, the meat becomes brown, which is highly undesirable. The formation of metmyoglobin is favoured by factors such as low $\mathrm{pH}$, increased salt concentration and UV light. The enzyme metmyoglobin reductase decreases the level of the undesirable form of myoglobin, thus stabilizes the colour of meat.

Beef tenderness is the ease of breakdown during biting and chewing. Many methods are available for instrumental determination of the degree of meat tenderness. Physical methods measure the force needed to shear, penetrate, detach, grind, compress or tear a meat sample. The indicator typically used to evaluate tenderness is shear force value, which measures the force needed to cut the sample perpendicular to the orientation of the muscle fibres. However, the correlation between this force and sensory tenderness is low (Purslow, 2005). Intramuscular proteins of the connective tissue and myofibrillar proteins are the components that significantly affect tenderness of beef. Their action is largely determined by the muscle type, structure and composition, and also by the heat treatment method and temperature (Brooks and Savell, 2004). Another essential factor influencing the ultimate tenderness of beef is how the meat is stored. At a temperature above the freezing point, meat is subject to the processes of aging, which increases its tenderness and shapes its taste. The changes that occur in meat as a result of endogenous proteolysis affect the structure and properties of both intramuscular connective tissue and muscle fibres. Connective tissue proteolysis during maturation of meat is reflected in increased collagen solubility, changes in mechanical properties of perimysium, and changes in the composition of proteoglycans (Kołczak et al., 2003; Purslow, 2005). During maturation, myofibril structure undergoes breakdown of Z-line sarcomeres, some myofibril regulatory proteins, and thick and thin filaments of cytoskeletal proteins which stabilize the spatial arrangement. The proteolytic changes in these proteins occur under the influence of endogenous sacroplasmic proteins - the calpains. The calpain system is represented by several isomeric cysteine proteases and their inhibitor calpastatin (Goll et al., 2003; Maddock et al., 2005). 


\section{Gene polymorphism vs slaughter value and beef quality}

It is difficult to improve meat quality traits based on conventional selection methods because they are polygenically regulated and lowly heritable. Moreover, the evaluation of these traits is expensive and can only be carried out postmortem. Knowledge about the genes and chromosome regions associated with desired meat quality characteristics may prove very helpful when selecting pairs for mating and estimating the breeding value of offspring.

Many studies have been conducted worldwide to determine the functions of various genes as well as their polymorphisms with potential effects on fattening and slaughter value of cattle and on beef quality. However, the effect of the analysed markers on different traits is not universal for all cattle breeds and cannot be extrapolated to the entire species (Gao et al., 2007; Reardon et al., 2010; Allais et al., 2011; Hirwa et al., 2011; Lozano et al., 2016).

Liu et al. (2015) while analyzing the effect of single nucleotide polymorphisms (SNPs) in seven epigenetic-related genes (DNMT1, DNMT3a, DNMT3b, DNMT3L, Ago1, Ago2, and HDAC5) and two meat quality candidate genes (CAPN1 and PRK$A G 3)$ in a Snow Dragon beef population found that 8 SNPs in DNMT1, DNMT3a, $D N M T 3 b$, and CAPN1 genes were significantly associated with carcass and beef quality traits. Genotyping of double muscled Piemontese young bulls made by Ribeca et al. (2014) revealed the associations between the investigated SNPs for growth hormone, growth hormone receptor, pro-opiomelanocortin, pro-opiomelanocortin class 1 homeobox 1, melanocortin-4 receptor, corticotrophin-releasing hormone, diacylglycerol O-acyltransferase-1, thyroglobulin, carboxypeptidase E and gamma-3 regulatory subunit of the AMP-activated protein kinase and the following traits: carcass weight, carcass daily gain and carcass conformation, whereas associations of the analysed SNPs with meat quality were moderate. The study of Reardon et al. (2010) on the association of SNPs in seven candidate genes with sensory and technological meat quality traits in crossbred Bos taurus commercial cattle revealed the effect of some polymorphisms on the water, intramuscular fat and protein content in bovine $m$. longissimus and $m$. semimembranosus. Hou et al. (2011 b) found that marbling score was significantly affected by the T354C, G392A, A430G and T433G SNP markers while the studies of Li et al. (2013), carried out on young bulls in Sweden, revealed that marbling was associated with the K232A polymorphism at the diacylglycerol O-acyltransferase 1 gene. LEP and SCD1 genes showed no association with variation of marbling but did with meat colour. According to Li et al. (2013) the UASMS2 polymorphism at the leptin gene and the SNPs at the stearoyl-CoA desaturase 1 gene were associated with the variation in meat colour traits after 6 days of exposure to air. A thorough study performed by Sevane et al. (2013) indicated the association between 26 SNPs located in 20 candidate genes and meat traits measured in 314 muscle samples of individuals belonging to 11 European bovine breeds. Similar investigation conducted by Dunner et al. (2013) on 15 European breeds of cattle, using 389 SNPs belonging to 206 candidate genes, showed a significant effect of PRKAG2 on the variation of m-calpain activity, CALM2 on calpastatin activity, CYP1A1 and PCSK1 on juiciness, DGAT2 on calpastatin activity and NEB on body weight at the age of 15 months. Also, SNPs in AANAT, CAST, CAPN1, CYP1A1, 
MADH3, MMP1, PLOD3, PGAM2, PPM2C and VIM genes were found to be associated with different traits related to meat tenderness, juiciness, physical characteristics and carcass performance.

The number of publications on the impact of different gene polymorphisms on the slaughter value and quality of beef is indeed large and constantly increasing, but when it comes to the relationship with the latter trait, the most research is focused on calpain and calpastatin. Studies concerning the myostatin gene polymorphism seem also relevant in this respect.

Pintos and Corva (2011) in association analyses carried out on Argentinian Angus cattle revealed that protease $\mu$-calpain, an enzyme involved in the process of tenderization of aged beef and this which encodes calpastatin, being a negative regulator of the calpains, were responsible for a high proportion of the genetic variation in beef tenderness. They also found that calpain/calpastatin complex seems to be involved in the regulation of growth, including birth weight, weaning weight, weight at 18 months and rib eye area. However, the effect of alleles favouring tenderness on growth traits was negative which should be taken into account when molecular markers are used in selection aimed at beef tenderness improvement. Polymorphisms in the calpastatin and $\mu$-calpain genes were shown to be related to meat tenderness/toughness also in French cattle breeds: Charolais, Limousin and Blonde d'Aquitaine (Allais et al., 2011). The nucleotide sequences in candidate genes such as the calpastatin gene, the stearoyl-CoA desaturase gene and the growth hormone receptor gene had an effect on sensory properties and technological parameters of bovine $m$. longissimus and $m$. semimembranosus (Reardon et al., 2010). The associations between some polymorphisms, located in calpain, calpastatin and cathepsin genes, and meat quality in Piemontese cattle were described also by Ribeca et al. (2013). Similar studies on the impact of CAPN1, CAST, and DGAT1 genes on meat traits in Angus, Hereford, Red Poll and Pinzgauer breeds were made by Tait et al. (2014).

Regarding the myostatin gene, Singh et al. (2014) claimed that it is an important candidate gene associated with growth and carcass composition in beef cattle. It significantly affects hot carcass weight, fat depth and marbling. In the study of Undarmaa et al. (2016) on Mongolian beef cattle breeds it was found that MSTN gene accounts for muscle development. It was demonstrated that the single nucleotide mutation in the third exon part of MSTN gene in Selenge breed caused phenotype which was considered as a meat trait.

\section{The $C A P N$ gene}

Calpains $(C A P N S)$ and calpastatin $(C A S T)$ are involved in a wide range of physiological processes including growth and differentiation of muscles, but also postmortem proteolysis and meat tenderization in domestic animals. Skeletal muscles of mammals contain three types of calpains: $C A P N 1$ ( $\mu$-calpain), CAPN2 (m-calpain) and tissue specific $C A P N 3$ (known as p94), as well as $C A S T$ being a $C A P N$ inhibitor. The opposite functions of the CAPNS and CAST genes make that meat tenderness increases with increasing ratio of calpains to calpastatin (Goll et al., 2003; Geesink et al., 2006; Koohmaraie and Geesink, 2006; Lian et al., 2013; Calvo et al., 2014). 


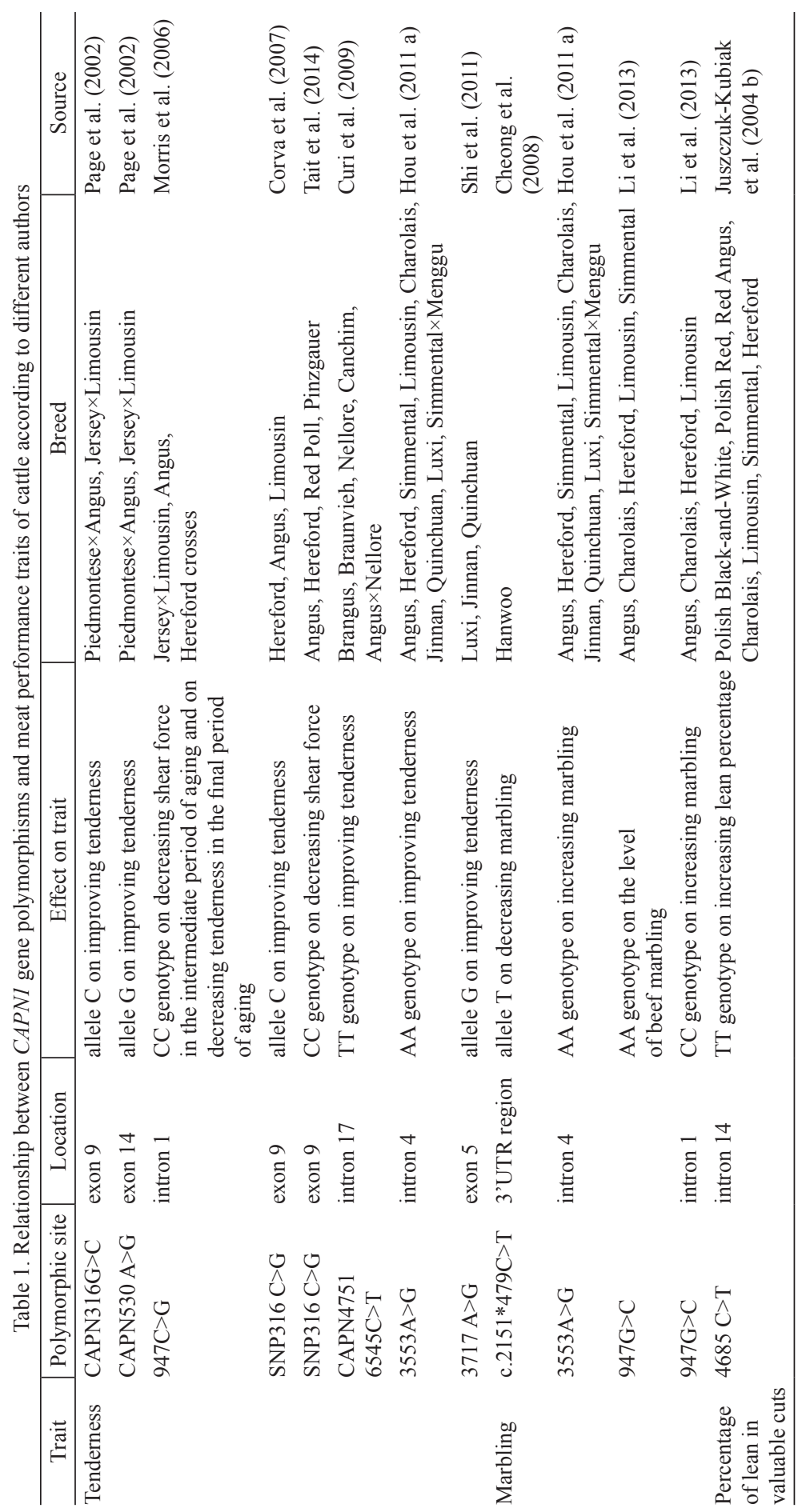


Calpains, responsible for the breakdown of myofibrillar proteins, are calciumion-activated neutral proteinases belonging to a group of cysteine endopeptidases (Goll et al., 2003; Calvo et al., 2014). CAPN1 is activated in the presence of $10-40 \mu \mathrm{M}$ calcium ion concentrations, and CAPN2 requires $1-2 \mathrm{mM} \mathrm{Ca}^{2+}$ for this purpose. The possibility of accelerating proteolysis through muscle incubation in calcium ion solution and its arrest under incubation with calcium ion chelators, argue for the effect of calpain on the tenderization process (Harris et al., 2001; Arrington et al., 2006). Proteolysis can be blocked by injection of zinc chloride, a calpain inhibitor (Lawrence et al., 2003 b). The CAPN1 gene is located on chromosome 29 and consists of 22 exons and 21 introns (Page et al., 2002; Juszczuk-Kubiak, 2004 b), while the CAPN2 gene is located on chromosome 16 and has 21 exons and 20 introns (www.ncbi.nlm.nih.gov/gene/?term=bos\%20taurus\%20capn2). CAPN3 has been established as an important activating enzyme specifically expressed in livestock's skeletal muscle, but its role in domestic animals meat tenderization remains controversial (Lian et al., 2013).

Xin et al. (2011), while analysing the polymorphism of CAPN1 in Chinese Yanbian Yellow cattle, found a tight correlation between variants of this gene and other quality traits as $\mathrm{pH}$, colour scores, fatty acid and amino acids contents. Liu et al. (2015) demonstrated the significant association of SNP15 (45219258C $>$ T) in CAPN1 gene alone or in combination with all 14 other SNPs with chuck short rib thickness and lean meat colour score which makes that this SNP can be used as a genetic marker in the selection for improvement in these beef traits.

A number of studies have analysed the effect of CAPN1 gene polymorphism on meat tenderness, marbling and shear force. Polymorphic sites within the CAPN1 gene were identified in both coding and non-coding regions. Table 1 lists selected polymorphisms identified in the CAPN1 gene as well as their effect on the mentioned meat characteristics in different breeds of cattle and their crossbreds. Page et al. (2002), by sequencing 22 exons and 19 introns of CAPN1 in Piedmontese $\times$ Angus and Jersey $\times$ Limousin cattle, identified 38 single nucleotide substitutions. Some of these substitutions resulted in alteration of the $\mu$-calpain amino acid sequence, for example in exon $9-\mathrm{G}>\mathrm{C}$ and in exon $14-\mathrm{A}>\mathrm{G}$. Alanine was substituted for glycine at position 316 of exon 9 and isoleucine for valine at position 530. In both cases, the polymorphism contributed to lower shear force value.

Juszczuk-Kubiak et al. (2004 b) analysed polymorphism in intron 14 of the $C A P N 1$ gene, being transition $\mathrm{C}>\mathrm{T}$ at position +4685 . The analysis was performed in bulls of various beef and dairy breeds, in which the CC, CT and TT genotypes were identified. However, not all of the genotypes were found in every breed. CC genotype was not observed in Charolais and CT genotype in the Angus breed. In the entire group of animals under study, allele $\mathrm{C}$ had a frequency of 0.62 and allele $\mathrm{T}$ a frequency of 0.38 . TT genotype was associated with increased lean meat in valuable cuts.

The results obtained by Morris et al. (2006) for the c.947C $>\mathrm{G}$ polymorphism suggest that CC genotype is associated with reduced shear force value in the intermediate period of meat aging and with increased tenderness in the final period. Differences between the values of these two measurements for CC and GG homozy- 
gotes were highly significant. The analysis involved Jersey $\times$ Limousin, Angus, and Hereford-cross cattle.

In turn, Corva et al. (2007) analysed the effect of $316 \mathrm{C}>\mathrm{G}$ polymorphism on meat tenderness in Hereford, Angus and Limousin cattle. Allele $\mathrm{C}$ was linked to improved tenderness, and the values of this trait for the meat from GG and $\mathrm{CC}$ homozygotes were statistically different. In the study of Pintos and Corva (2011) on CAPN316, CAPN4751, CAPN1 and CAST2 markers in Angus cattle, alleles C, $\mathrm{C}, \mathrm{A}$ and $\mathrm{C}$, respectively, were considered to be associated with higher beef tenderness.

The analyses of the c. $2151 * 479 \mathrm{C}>\mathrm{T}$ polymorphism, located in the 3 'UTR region, made by Cheong et al. (2008), revealed that the allele T was responsible for lower marbling in Korean Hanwoo cattle. The intramuscular fat content was lowest in TT homozygotes and highest in CC homozygotes.

The extent of myofibril degradation can be evaluated with the myofibrillar fragmentation index (MFI), which is correlated with instrumental tenderness of meat (Lawrence et al., 2003 a). Curi et al. (2009) analysed the effect of g.6545C $>$ T polymorphism in intron 17 of the CAPN1 gene in various breeds of Bos indicus and Bos indicus $\times$ Bos taurus cattle. The obtained results showed that TT genotype was related to lower shear force and MFI. Measurements for the TT homozygotes and CT heterozygotes differed significantly. CC genotype was not statistically analysed due to low frequency.

In a study on Angus, Hereford, Simmental, Limousin, Charolais, Jinnan, Quinchuan, Luxi, and Simmental $\times$ Menggu cattle, Hou et al. (2011 a) demonstrated the effect of $3553 \mathrm{~A}>\mathrm{G}$ polymorphism on marbling of meat. No AA homozygotes were noted among Hereford, Limousin, Luxi and Charolais breeds. In case of meat from other breeds, AA homozygotes were characterized by significantly higher marbling compared to meat from animals of AG and GG genotypes. In addition, meat tenderness showed highly significant differences according to genotype.

Li et al. (2013) while analysing c.947G $>$ C polymorphism in Angus, Charolais, Hereford and Limousin breeds found that animals of CC genotype were characterized by greater marbling than $\mathrm{CG}$ and $\mathrm{GG}$ animals. The $C A P N 1$ polymorphism was also associated with meat colour (hue angle) after 6 days of exposure to air.

Shi et al. (2011), who analysed polymorphism at position $3717 \mathrm{~A}>\mathrm{G}$ in Luxi, Jinnan and Qinchuan cattle, demonstrated the effect of genotype on Warner-Bratzler shear force (WBSF). The meat from animals of AA genotype showed significantly greater toughness compared to others. At the same time, no significant differences were observed between shear force values for the AG and GG genotypes.

Lozano et al. (2016), while analysing $C A P N$ and combined effect of $C A P N$ and $C A S T$ on meat tenderness pointed out the differences in gene effects between Bos indicus, Bos taurus and their crossbreds. They found that the CAPN316 genetic marker is a potential tenderness predictor for 14-day-old commercial bovine meat. It significantly affected WBSF, favouring a reduction in allelic substitution effect of more than $0.500 \mathrm{~kg}$ by C allele. Similarly, for CAPN4751 the allelic substitution effect produced a significant reduction of WBSF (more than $0.300 \mathrm{~kg}$ ) by favourable $\mathrm{C}$ allele. 


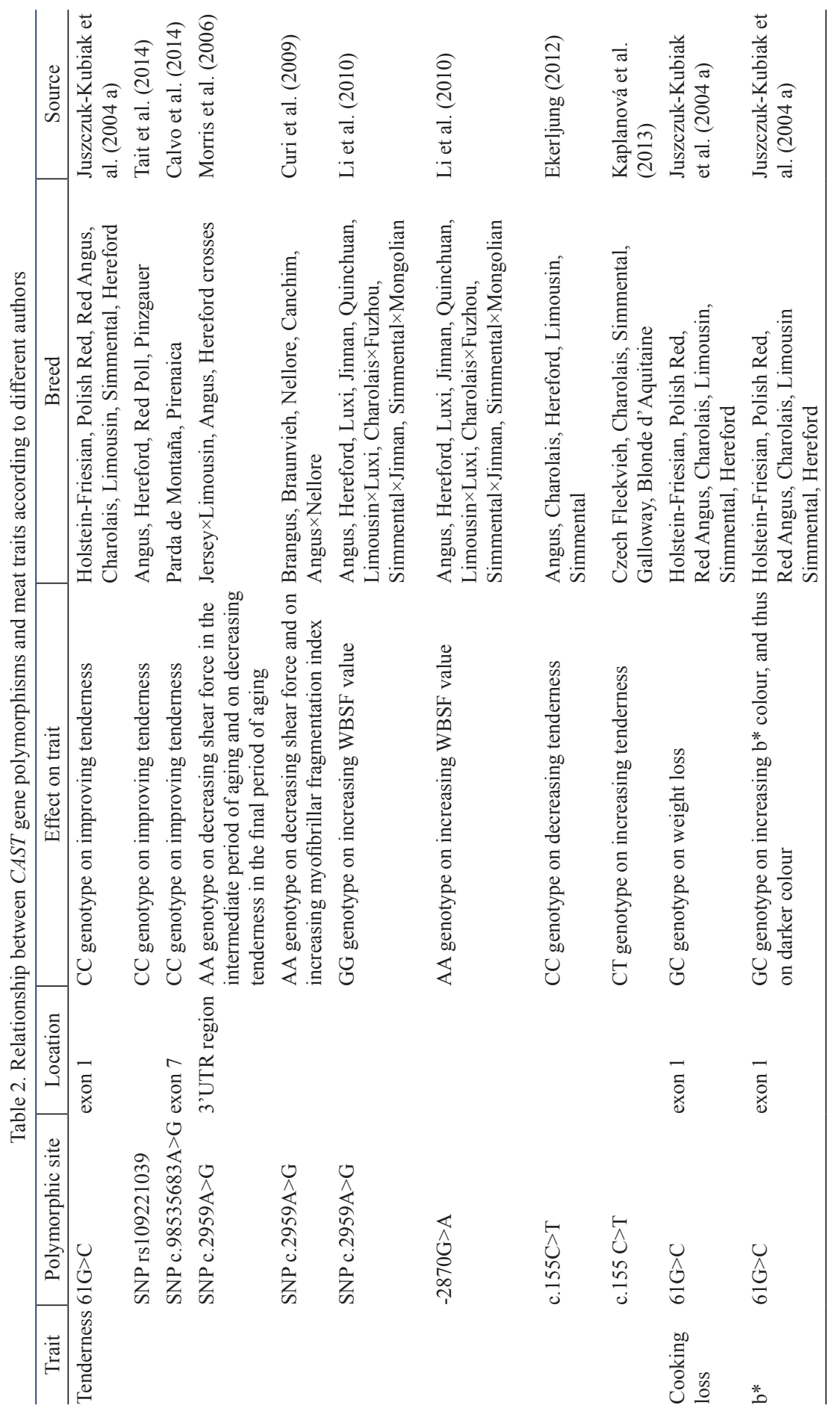




\section{The CAST gene}

The activity of calpastatin varies in different muscles of the same carcass and contributes to differences in the degradation of muscle cytoskeletal proteins postmortem (Melody et al., 2004). The bovine calpastatin gene (CAST) is located on chromosome 7. It has five SNPs (CAST1, CAST2, CAST3, CAST4, CAST5) which act as endogenous inhibitors of the proteolytic activity of calpains. Studies on the association of all these SNPs with meat tenderness in the Parda de Montaña and Pirenaica breeds were decribed by Calvo et al. (2014).

In Table 2 selected polymorphisms identified in the CAST gene with their effects on meat traits in different cattle breeds and crossbreds are listed.

Juszczuk-Kubiak et al. (2004 a) identified polymorphism in exon 1, being $\mathrm{G}>\mathrm{C}$ transversion in $61 \mathrm{bp}$ position which resulted in a serine to threonine change in position 20 of the calpastatin protein. The study was performed on 138 bulls representing 5 beef breeds as well as the Polish Red and Black-and-White Lowland dairy breeds. This research identified two alleles (C and $\mathrm{G}$ ) and three genotypes (CC, CG and GG). Frequency of the $\mathrm{C}$ allele was 0.69 and the $\mathrm{G}$ allele had a frequency of 0.31 . The presence of the GC genotype increased cooking loss of meat and the differences were significant compared to the $\mathrm{CC}$ genotype and highly significant in relation to the GG genotype. Furthermore, the GC genotype increased the $b^{*}$ colour value, making the meat darker. Also in this case there were differences between heterozygotes and homozygotes $(\mathrm{GG}-\mathrm{P} \leq 0.01 ; \mathrm{CC}-\mathrm{P} \leq 0.05)$. Sensory analysis showed the effect of the $\mathrm{CC}$ genotype on improving tenderness as well as a significant difference between the $\mathrm{CC}$ and $\mathrm{GC}$ genotypes.

Morris et al. (2006) analysed the effect of the 2959A $>$ G polymorphism on beef traits in Jersey $\times$ Limousin, purebred Angus and Hereford-crosses. By comparing the AA and AG genotypes, the authors found the meat from homozygotes to be characterized by lower shear force in the intermediate period of aging and decreased tenderness at the end of the aging period. In both cases, highly significant differences were noted. The GG genotype was not frequent, which did not allow the authors to determine its statistical effect on the analysed traits.

Curi et al. (2009), who studied the same polymorphic site (2959A $>\mathrm{G})$ in Bos indicus and Bos indicus $\times$ Bos taurus cattle, demonstrated that AA homozygotes were characterized by lower shear force and higher myofibrillar fragmentation index compared to heterozygotes. The GG genotype occurred in only $1 \%$ of the animals, which made it impossible to determine its effect on meat traits, as was the case in the study by Morris et al. (2006).

Other studies concerning the above mentioned polymorphism in Angus, Hereford, Luxi, Jinnan, Quinchuan, Limousin $\times$ Luxi, Charolais $\times$ Fuzhou, Simmental $\times$ Jinnan and Simmental $\times$ Mongolian breeds revealed higher Warner-Bratzler shear force for the GG genotype than for the other genotypes. For another polymorphism, $2870 \mathrm{G}>\mathrm{A}$, AA homozygotes showed poorer meat tenderness and thus higher WBSF value ( $\mathrm{Li}$ et al., 2010).

Ekerljung (2012) reported the effect of c.155C $>\mathrm{T}$ polymorphism on beef tenderness in Angus, Charolais, Hereford, Limousin and Simmental breeds. The meat of animals with $\mathrm{CC}$ genotype was tougher than the meat from animals of $\mathrm{CT}$ and 
TT genotypes, and the differences were highly significant. Also, Kaplanová et al. (2013), in the study of the c.155C $>$ T polymorphism in Czech Fleckvieh, Charolais, Beef Simmental, Galloway and Blonde d'Aquitaine breeds, showed that meat was more tender in TT homozygotes, shear force was the lowest in CT heterozygotes and higher for animals of CC genotype. However, unlike the authors cited above, Li et al. (2013) found no association between the SNP at CAST:c.155 and meat quality traits.

Calvo etal.(2014) observed that three SNPs located at intron 5(BTA7: g.98533962C $>$ G on UMD 3.0), exon 7 (g.98535683A $>\mathrm{G}$ ) and intron 12 (g.98545188T $>\mathrm{A}$ ) of the CAST gene in the Parda de Montaña breed were significantly associated with meat tenderness at 7 days postmortem. The GG genotype yielded less tender beef than AG and AA genotypes. This finding may be useful for the beef industry to identify tough meat and design adequate handling procedures for the carcasses.

\section{The MSTN gene}

Polymorphism of the myostatin $(M S T N)$ gene was analysed in various species of animals such as mice (Mendias et al., 2008), dogs (Mosher et al., 2007; Shelton and Engvall, 2007), sheep (Clop et al., 2006; Hickford et al., 2009), pigs (Tu et al., 2012) and horses (Dall'Olio et al., 2010; Hill et al., 2010). The high interest in the MSTN gene stems from the fact that its polymorphism may be associated with muscular hypertrophy. In cattle, the MSTN gene polymorphism has an effect on various meat performance traits (Table 3).

Because myostatin is involved in differentiation of muscle fibres during growth, the polymorphism of the gene coding for this protein may influence muscle fibre thickness and the frequency of red, white and intermediate fibres in the muscles (Siegel and Massagué, 2003), and thus can be considered one of the factors affecting beef quality. Meat tenderness was found to increase when the muscles have lower fibre diameter, and for thicker fibres the proteolytic process is longer, which has a significant effect on tenderization.

The MSTN gene, also known as GDF8 (growth differentiation factor 8), is located on chromosome 2 in cattle. It contains three exons and two introns and spans $6690 \mathrm{bp}$. The first and second exons span 506 and $374 \mathrm{bp}$, respectively. The length of the third exon varies at 1701, 1812 and 1887 bp (Jeanplong et al., 2001). Spiller et al. (2002) and Crisà et al. (2003) analysed the MSTN gene promoter in cattle (Marchigiana, Chianina, Romagnola, Piedmontese, Holstein-Friesian, Italian Red Pied, Swiss Brown, Belgian Blue, Limousin) and found it to be considerably conservative compared to the analogous gene fragment in other species of animals. Among the 10 E-box sequences found in the bovine gene promoter, the authors highlighted sequence E6, which has an effect on expression of the reporter gene in $\mathrm{C}_{2} \mathrm{C}_{12}$ cells and binds the MyoD myogenic regulatory factor in vivo and in vitro. This factor was observed to act as a positive regulator of myostatin expression in myoblasts. Myostatin regulates cell cycle progression of myoblasts (G1 to S-phase transition). It is proposed that the MyoD factor, by regulating myostatin expression, may regulate the cell cycle of myoblasts, among others by inhibiting muscle development (Spiller et al., 2002). In the promoter region of the MSTN gene in cattle, binding sites for many other transcription factors were also detected (Spiller et al., 2002; Crisà et al., 2003; Zhang et al., 2007). 


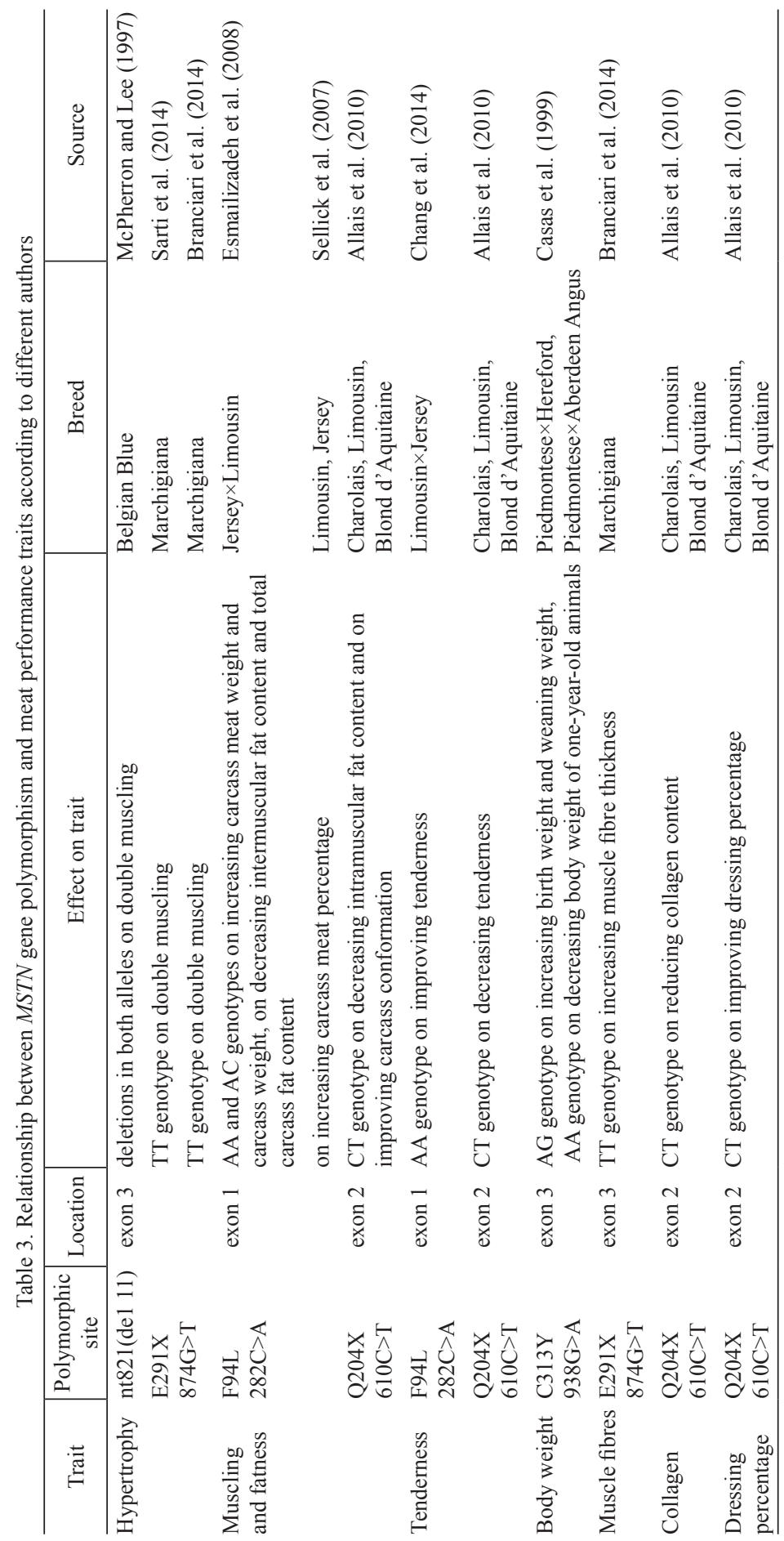


The analysis of MSTN gene expression and myogenic factors during development of cattle muscles with and without hypertrophy showed the highest MSTN transcript level during formation of secondary muscle fibres. The expression level of the MSTN gene was higher in hypertrophic animals. MyoD expression proved to be highest during the formation of primary and secondary fibres and was also higher in cattle with hypertrophy. The expression of MSTN and MyoD was also observed to increase parallel to the formation of muscle fibres, so it can be presumed that these factors may be involved in muscle differentiation or myoblast fusion (Oldham et al., 2001).

In cattle, the gene encoding myostatin was discovered by McPherron and Lee (1997) in Belgian Blue and Piedmontese breeds, in which muscles hypertrophy (socalled "double muscling") resulted from nt821(del11) deletion in exon 3. This deletion induces a premature stop codon and leads to the formation of biologically inactive protein, which is manifested in excessive growth of skeletal muscles. The muscle weight of double-muscled animals is an average of $20 \%$ higher than that in animals without the deletion. nt821(del11) deletion in exon 3 increases the number and diameter of muscle fibres (Kambadur et al., 1997). Double muscling was also detected in the individuals of Charolais, Blonde d'Aquitaine, Limousin, Parthenaise, Gasconne, Maine-Anjou, Asturiana de los Valles, Marchigiana and Rubia Gallega cattle, however, not in all of them the deletion of $11 \mathrm{bp}$ at nucleotide position $821 \mathrm{was}$ found, which may suggest other factors/mutations contributing to this phenotype (Grobet et al., 1998; Bongiorni et al., 2016). An overview of the main mutations of the MSTN gene in individuals of cattle breeds showing hereditary muscular hyperplasia was included in the paper of Bongiorni et al. (2016), who also revealed how transition $\mathrm{G}>\mathrm{A}$ at nucleotide position 938, resulting in the substitution of a cysteine by a tyrosine (mutation $\mathrm{C} 313 \mathrm{Y}$ ), affects the structure and function of MSTN gene in double-muscled Piedmontese cattle.

What is interesting, Wiener et al. (2009) found that the myostatin allele with the 11-bp deletion $(\mathrm{MH})$ segregating in the South Devon cattle breed caused decreased growth rate, carcass weight, muscle conformation and levels of saturated and monounsaturated fatty acids as well as increased ratio of polyunsaturated (PUFA) to saturated fatty acids (SFA).

Another mutation in the bovine $M S T N$ gene is F94L, located in a highly conservative region, coding for the $\mathrm{N}$-terminal protein domain. It is a $\mathrm{C}>\mathrm{A}$ transversion in position 282 of exon 1, resulting in a phenylalanine to leucine substitution in position 94 of the encoded protein (Bellinge et al., 2005). In Jersey and Limousin breeds some animals carried both mutated alleles, but this genotype had no effect on the presence of double muscling. It follows therefore that this mutation does not affect the myostatin protein to such a degree as nt821(del11) (Joulia-Ekaza and Cabello, 2006). In a study by Esmailizadeh et al. (2008) on Jersey $\times$ Limousin cattle, the F94L mutation had no significant effect on the birth weight and growth rate of the calves. In turn, the analysis of slaughter traits showed increased carcass meat weight (by 6.5\%) and carcass weight (by almost 16\%), and decreased intermuscular fat content (by 7.5\%) and total carcass fat (by 8-16.5\%). Sellick et al. (2007) noted a higher carcass meat percentage (by $2.3 \%$ ) in heterozygous Limousin and Jersey 
animals. Chang et al. (2014), who analysed the F94L mutation in Limousin $\times$ Jersey bulls, showed its effect on beef tenderness. The results obtained for the analysis of shear force indicated that the meat from AA homozygotes was characterized by best tenderness, whereas poorest tenderness was found in animals of CC genotype.

The mutation, which probably induces a premature stop codon (UAG) is Q204X (610 $\mathrm{C}>\mathrm{T}$ transition in exon 2 ). When examining the presence of this mutation in the Charolais, Limousin and Blonde d'Aquitaine breeds, Allais et al. (2010) found that some animals were heterozygous and none of the animals carried the mutation in both alleles. The polymorphism was most frequent in the Charolais breed. The authors suggested its relationship with tougher meat, lower carcass fatness, lower content of intramuscular fat and collagen. Heterozygous animals exhibited better carcass conformation and dressing percentage compared to the mutation-free animals. The Limousin and Charolais animals, being heterozygous for the Q204X and nt821 polymorphisms, were characterized by better carcass conformation and dressing percentage compared to the animals with homozygous genotypes ( $\mathrm{CC}$ and those without deletion of 11 nucleotides in any of the alleles, respectively), and these differences were highly significant.

In turn, Sarti et al. (2014) analysed the MSTN gene polymorphism at position g874 $\mathrm{G}>\mathrm{T}$ in the Marchigiana breed and observed the double muscling phenotype in TT homozygotes, but these animals were characterized by shorter survival. The effects of the TT genotype on increasing muscling and increasing thickness of muscle fibres in above mentioned breed were also found by other authors (Branciari et al., 2014). Bouyer et al. (2014) identified an unexpected T3811.G3811 mutation within intron 2 of the MSTN gene that most likely contributes to muscular hypertrophy in Blonde d'Aquitaine cattle. So far approximately 20 different types of genetic variants (deletions, insertions and SNPs) have been detected in the bovine MSTN. A relatively detailed summary of the identified MSTN variants in cattle breeds (mainly Belgian Blue, Piemontese, Marchigiana) and their effect on beef traits, including hypertrophy, was given in the review of Aiello et al. (2018). What is more, a recent study of Bennett et al. (2019) demonstrated that beef traits such as: marbling score, rib eye area, adjusted fat thickness, vision yield grade, slice shear force and CIE L* reflectance were significantly affected by the interactions between MSTN and $C A P N 1$ genotypes (3 CAPN1 diplotypes $\times 3$ F94L genotypes).

To date research proved that the important meat quality traits in cattle are influenced by single or combined polymorphisms in various genes. However, only a full understanding of the underlying molecular mechanisms will allow for effective improvement of these traits, which in turn can contribute to increasing the profitability of beef industry. In this context, further association studies carried on large populations of different breeds appear to be justified.

\section{References}

A i e 11 o D., P a te 1 K., L a s a g a E. (2018). The myostatin gene: an overview of mechanisms of action and its relevance to livestock animals. Anim. Gen., 49: 505-519. 
A 11 a is S., Levéziel H., Payet-Duprat N., Hocquette J.F., Le petit J., Rous set S., Denoyelle C., Bernard-Capel C., Journaux L., Bonnot A., Renand G. (2010). The two mutations, Q204X and nt821, of the myostatin gene affect carcass and meat quality in young heterozygous bulls of French beef breeds. J. Anim. Sci., 88: 446-454.

Alla is S., Journaux L., Levéziel H., Payet-Duprat N., Raynaud P., Hocquet te J.F., Lepetit J., Rousset S., Denoyelle C., Bernard-Capel C., Renand G. (2011). Effects of polymorphisms in the calpastatin and $\mu$-calpain genes on meat tenderness in 3 French beef breeds. J. Anim. Sci., 89: 1-11.

Arrington D.D., Van Vleet T.R., S chnellmann R.G. (2006). Calpain 10: a mitochondrial calpain and its role in calcium-induced mitochondrial dysfunction. Am. J. Physiol.-Cell Physiol., 291: C1159-C1171.

B elling e R.H.S., L ib e r le s D.A., I a s ch i S.P.A., O 'B rie n P.A., Ta y G.K. (2005). Myostatin and its implications on animal breeding: a review. Anim. Gen., 36: 1-6.

B e nne t t G.L., Ta it Jr. R.G., Shackelford S.D., Whe eler T.L., King D.A., C a s a s E., $\mathrm{S} \mathrm{m}$ ith T.P.L. (2019). Enhanced estimates of carcass and meat quality effects for polymorphisms in myostatin and $\mu$-calpain genes. J. Anim. Sci., 97: 569-577.

B ongiorni S., Valentini A., Chillemi G. (2016). Structural and dynamic characterization of the $\mathrm{C} 313 \mathrm{Y}$ mutation in myostatin dimeric protein, responsible for the "double muscle" phenotype in Piedmontese cattle. Front. Genet., 7: 14.

B o u y e r C., F or e sti e r L., Ren and G., O u 1 mouden A. (2014). Deep intronic mutation and pseudo exon activation as a novel muscular hypertrophy modifier in cattle. PLoS ONE, 9(5): e97399.

Branciari R., Ceccobelli S., Di Lorenzo P., Ranucci D., Miraglia D., Codini M., C e c c a r in i M.R., L a s a g a E. (2014). Characterization of muscle fibers in normal and hypertrophied Marchigiana beef cattle. J. Biotechnol., 185: S42.

B r o o k s J.C., S a ve 11 J. (2004). Perimysium thickness as an indicator of beef tenderness. Meat Sci., 67: 329-334.

Calvo J.H., I g uáce 1 L.P., K irinus J.K., S e rrano M., Ripoll G., C a s a sú s I., J oy M., Pérez-Velas co L., S arto P., A lbertí P., B lanco M. (2014). A new single nucleotide polymorphism in the calpastatin (CAST) gene associated with beef tenderness. Meat Sci., 96, Part A: $775-782$.

C a s a E E., Ke ele J.W., Fahrenkrug S.C., S mith T.P., Cund iff L.V., S tone R.T. (1999). Quantitative analysis of birth, weaning, and yearling weights and calving difficulty in Piedmontese crossbreds segregating an inactive myostatin allele. J. Anim. Sci., 77: 1686-1692.

Chang L.Y., Pitchford W.S., B ottema C.D.K. (2014). Modeling tenderness for genetic and quantitative trait loci analyses. J. Anim. Sci., 92: 39-47.

Cháv e z A., Pér e z E., Rubio M.S., Mén de z R.D., De lg a do E.J., Día z D. (2012). Chemical composition and cooking properties of beef forequarter muscles of Mexican cattle from different genotypes. Meat Sci., 91: 160-164.

Cheong H.S., Yoon D.H., Park B.L., Kim L.H., B a e J.S., Namgoong S., Lee H.W., $\mathrm{H}$ a n C.S., K i m J.O., C h e ong I.C., S h in H.D. (2008). A single nucleotide polymorphism in CAPN1 associated with marbling score in Korean cattle. BMC Gen., 9: 33.

Clop A., Marcq F., Takeda H., Pirottin D., Tordoir X., Bibé B., Bouix J., Caiment F., Elsen J.M., Eychenne F., Larzul C., Laville E., Meish F., Milenkovic D., Tobin J., Charlie r C., G e orge s M. (2006). A mutation creating a potential illegitimate micro RNA target site in the myostatin gene affects muscularity in sheep. Nat. Gen., 38: 813-818.

Corva P., Soria L., Schor A., Villarreal E., Pérez Cenci M., Motter M., Mezzadra C., Melucci L., Miguel C., Paván E., Depetris G., Santini F., Grigera $\mathrm{N}$ a ó n J. (2007). Association of CAPN1 and CAST gene polymorphisms with meat tenderness in Bos taurus beef cattle from Argentina. Gen. Mol. Biol., 30: 1064-1069.

Cris à A., M a r chitelli C., S a vare se M.C., Valentin i A. (2003). Sequence analysis of myostatin promoter in cattle. Cytogenet. Genome Res., 102: 48-52.

Curi R.A., Chardulo L.A.L., Mason M.C., Arrigoni M.D.B., Silveira A.C., de Olive ir a H.N. (2009). Effect of single nucleotide polymorphisms of CAPN1 and CAST genes on meat traits in Nellore beef cattle (Bos indicus) and in their crosses with Bos taurus. Anim. Gen., 40: $456-462$. 
Dall'Olio S., Fontanesi L., Nanni Costa L., Tassinari M., Minieri L., Falas chini A. (2010). Analysis of horse myostatin gene and identification of single nucleotide polymorphisms in breeds of different morphological types. J. Biomed. Biotechnol., ID 542945, doi: $10.1155 / 2010 / 542945$.

Dunner S., S evane N., García D., Cortés O., Valent ini A., Wi 11 i a m s J.L., Mang in B., Cañón J., L e vé zi e l H., the GeMQual Consortium (2013). Association of genes involved in carcass and meat quality traits in 15 European bovine breeds. Livest. Sci., 154: 34-44.

Ekerljung M. (2012). Candidate gene effect on beef quality. Licentiate thesis. Swedish University of Agricultural Sciences Uppsala.

Esmailizadeh A.K., B otte ma C.D., Sellick G.S., Verbyla A.P., Morris C.A., Cu 1 len N.G., Pitchford W.S. (2008). Effects of the myostatin F94L substitution on beef traits. J. Anim. Sci., 86: 1038-1046.

G a o Y., Zhang R., Hu X., Li N. (2007). Application of genomic technologies to the improvement of meat quality of farm animals. Meat Sci., 77: 36-45.

G e e s in k G.H., K u c ha y S., Ch i s h t i A.H., K o o h m a ra i e M. (2006). $\mu$-Calpain is essential for postmortem proteolysis of muscle proteins. J. Anim. Sci., 84: 2834-2840.

Goll D.E., Thomps on V.F., Li H.Q., We i W., Cong J.Y. (2003). The calpain system. Physiol. Rev., 83: 731-801.

Grobet L., Poncelet D., Royo L.J., Brouwers B., Pirottin D., Michaux C., Men is sier F., Zanotti M., Dunner S., Georges M. (1998). Molecular definition of an allelic series of mutations disrupting the myostatin function and causing double-muscling in cattle. Mamm. Genome, 9: 210-213.

Harris S.E., H u ff - L o ne rgan E., L o nergan S.M., J o n e s W.R., R a n k in s D. (2001). Antioxidant status affects color stability and tenderness of calcium chloride-injected beef. J. Anim. Sci., 79: 666-667.

H i c kford J.G., F orrest R.H., Z hou H., F ang Q., Ha n J., Fra m p to n C.M., H or re 11 A.L. (2009). Polymorphisms in the ovine myostatin gene (MSTN) and their association with growth and carcass traits in New Zealand Romney sheep. Anim. Gen., 41: 64-72.

Hill E.W., Gu J., Eivers S.S., Fonseca R.G., McGivney B.A., Govindarajan P., Orr N., Katz L.M., Mac Hugh D.E. (2010). A sequence polymorphism in MSTN predicts sprinting ability and racing stamina in thoroughbred horses. PLOS One, 5 (1): e8645.

Hirwa C.A., Wallace P., Shen X., Nie Q., Yang G., Zhang X. (2011). Genes related to economically important traits in beef cattle. Asian J. Anim. Sci., 5: 34-45.

Hou G., Huang M., Ga o X., Li J., Ga o H., Ren H., Xu S. (2011 a). Associations of calpain 1 (CAPN1) and HRSP12 allelic variants in beef cattle with carcass traits. Afr. J. Biotechnol., 10: 13714-13718.

Hou G.Y., Yuan Z.R., Zhou H.L., Zhang L.P., Li J.Y., Ga o X., Wang D.J., Gao H.J., $\mathrm{X}$ u S.Z. (2011 b). Association of thyroglobulin gene variants with carcass and meat quality traits in beef cattle. Mol. Biol. Rep., 38: 4705-4708.

I s o- Touru T., P e s on en M., F is cher D., Hu u s konen A., S ironen A. (2018). The effect of CAPN1 and CAST gene variations on meat quality traits in Finnish Aberdeen Angus and Nordic Red Cattle populations. Agr. Food. Sci., 27: 227-231.

J eanplong F., Sharma M., Somers W.G., B a s s J.J., Kambadur R. (2001). Genomic organization and neonatal expression of the bovine myostatin gene. Mol. Cell. Biochem., 220: 31-37.

J o u lia-Ekaza D., Cabello G. (2006). Myostatin regulation of muscle development: molecular basis, natural mutations, physiopathological aspects. Exp. Cell Res., 312: 2401-2414.

Juszczuk-Kubiak E., Rosochacki S.J., Wicińska K., Szreder T., Sakowski T. (2004 a). A novel RFLP/AluI polymorphism of the bovine calpastatin (CAST) gene and its association with selected traits of beef. Anim. Sci. Pap. Rep., 22: 195-204.

Juszczuk-Kubiak E., Sakowski T., Flis ikowski K., Wi cińska K., Oprządek J., R o s o c h a c k i S.J. (2004 b). Bovine $\mu$-calpain (CAPN1) gene: new SNP within intron 14. J. App. Gen., 45: 457-460.

K a m b a d ur R., S h arm a M., S m it h T.P.L., B a s s J.J. (1997). Mutations in myostatin (GDF-8) in double muscled Belgian Blue and Piedmontese cattle. Genome Res., 7: 910-915. 
Kaplanová K., Dufek A., Dračková E., Simeonovová J., Šubrt J., Vrtková I., D v o ŕá k J. (2013). The association of CAPN1, CAST, SCD and FASN polymorphisms with quality traits in commercial crossbread cattle in the Czech Republic. Czech J. Anim. Sci., 58: 489-496.

K e a n e M.G., D unne P.G., Kenny D.A., B erry D.P. (2011). Effect of genetic merit for carcass weight, breed type and slaughter weight on performance and carcass traits of beef $\times$ diary steers. Animal, 5: 182-194.

K ołc zak T., P ałka K., P ośpie ch E. (2003). Changes in collagen solubility of raw and roasted bovine psoas major and minor and semitendinosus muscles during cold storage. Pol. J. Food Nutr. Sci., 12/53: 57-61.

K o o h m a rai e M., Ge e s in k G.H. (2006). Contribution of postmortem muscle biochemistry to the delivery of consistent meat quality with particular focus on the calpain system. Meat Sci., 74: 34-43.

L a w r e n c e T.E., D i k e m a n M.E., Hun t M.C., K a s tn e r C.L., J o h n s o n D.E. (2003 a). Staged injection marination with calcium lactate, phosphate and salt may improve beef water-binding ability and palatability traits. Meat Sci., 65: 967-972.

Law rence T.E., Dikeman M.E., Stephens J.W., Obuz E., Davis J.R. (2003 b). In situ investigation of the calcium-induced proteolytic and saltingin mechanisms causing tenderization in calcium-enhanced muscle. Meat Sci., 66: 69-75.

Li J., Zhang L.P., Gan Q.F., Li J.Y., Ga o H.J., Yuan Z.R., Ga o X., Chen J.B., Xu S.Z. (2010). Association of CAST gene polymorphisms with carcass and meat quality traits in Chinese commercial cattle herds. Asian-Australas. J. Anim. Sci., 23: 1405-1411.

L i X., Ekerljung M., Lundström K., Lundén A. (2013). Association of polymorphisms at DGAT1, leptin, SCD1, CAPN1 and CAST genes with color, marbling and water holding capacity in meat from beef cattle populations in Sweden. Meat Sci., 94: 153-158.

L i a n T., Wang L., L i u Y. (2013). A new insight into the role of calpains in post-mortem meat tenderization in domestic animals: A review. Asian-Australas. J. Anim. Sci., 26: 443-454.

Liu X., Usman T., Wang Y., Wang Z., Xu X., Wu M., Zhang Y., Zhang X., Li 1 Q., Liu L., Shi W., Q in C., Geng F., Wang C., Tan R., Huang X., Li u A., Wu H., Tan S., Yu Y. (2015). Polymorphisms in epigenetic and meat quality related genes in fourteen cattle breeds and association with beef quality and carcass traits. Asian-Australas. J. Anim. Sci., 28: 467-475.

Lozano M.S.R., A 1 faro-Zavala S., Sifuentes-Rincón A.M., Parra-Bracamonte G.M., Var ela D.B., Ménde z Medina R.D., L in ares C.P., R in cón F.R., E s c a lante A.S., Torrescano Urrutia G., Figueroa Sa avedra F. (2016). Meat tenderness genetic and genomic variation sources in commercial beef cattle. J. Food Qual., 39: 150-156.

M a ch N., B a ch A., Velard e A., D e v a n t M. (2008). Association between animal, transportation, slaughterhouse practices, and meat $\mathrm{pH}$ in beef. Meat Sci., 78: 232-238.

Madd o ck K.R., Huff-L on ergan E., R ow e L.J., L on erga n S.M. (2005). Effect of pH and ionic strength on $\mu$ - and m-calpain inhibition by calpastatin. J. Anim. Sci., 83: 1370-1376.

Magolski J.D., Buchanan D.S., Maddock-Carlin K.R., Anderson V.L., Newman D.J., B erg E.P. (2013). Relationship between commercially available DNA analysis and phenotypic observations on beef quality and tenderness. Meat Sci., 95: 480-485.

Mc Pherron A.C., Lee S.J. (1997). Double muscling in cattle due to mutations in the myostatin gene. Proceedings of the National Academy of Sciences of the USA. 94: 12457-12461.

M e l o d y J.L., L o n e r g a n S.M., R o w e L.J., H u i a t t T.W., M a y e s M.S., H u ff - L o n e r g a n E. (2004). Early post mortem biochemical factors influence tenderness and water-holding capacity of three porcine muscles. J. Anim. Sci., 82: 1195-1205.

Mendi a s C.L., B a k h u r in K.I., F a u $1 \mathrm{kn}$ e r J.A. (2008). Tendons of myostatin-deficient mice are small, brittle and hypocellular. Proceedings of the National Academy of Sciences of the USA. 105: 388-393.

Morris C.A., Culle n N.G., Hi cke y S.M., D obbi e P.M., Ve envli et B.A., Manley T.R., P it ch ford W.S., Kruk Z.A., B ot te m a C.D.K., Wilson T. (2006). Genotypic effects of calpain 1 and calpastatin on the tenderness of cooked M. longissimus dorsi steaks from Jersey $\times$ Limousin, Angus and Hereford - cross cattle. Anim. Gen., 37: 411-414.

Mosher D.S., Quignon P., Bustamante C.D., Sutter N.B., Mellersh C.S., Park e r H.G., O s tran d e r E.A. (2007). A mutation in the myostatin gene increases muscle mass and enhances racing performance in heterozygote dogs. PLOS Genetics, 3 (5): e79. 
Oldham J.M., Martyn J.A.K., Sharma M., Jeanplong F., Kambadur R., Bas s J.J. (2001). Molecular expression of myostatin and MyoD is greater in double-muscled than normalmuscled cattle fetuses. Am. J. Physiol. Regul. Integr. Comp. Physiol., 280: 1488-1493.

P a g e B.T., C a s a s E., He a t on M.P., Culle n t N.G., H y n d m a n D.L., Morris C.A., C r a w ford A.M., Whe eler T.L., K o ohm araie M., K e ele J.W., S m ith T.P.L. (2002). Evaluation of single-nucleotide polymorphism in CAPN1 for association with meat tenderness in cattle. J. Anim. Sci., 80: 3077-3085.

P intos D., Corva P.M. (2011). Association between molecular markers for beef tenderness and growth traits in Argentinian Angus cattle. Anim. Gen., 42: 329-332.

Purs low P.P. (2005). Intramuscular connective tissue and its role in meat quality. Meat Sci., 70: 435-447.

Reardon W., Mullen A.M., Swe eney T., Hamill R.M. (2010). Association of polymorphisms in candidate genes with colour, water-holding capacity, and composition traits in bovine m. longissimus and m. semimembranosus. Meat Sci., 86: 270-275.

Resurreccion A.V.A. (2004). Sensory aspects of consumer choices for meat and meat products. Meat Sci., 66: 11-20.

Ribeca C., B onfatti V., C e c chinato A., A lbera A., Maretto F., Gallo L., Carnier P. (2013). Association of polymorphisms in calpain 1, (mu/I) large subunit, calpastatin, and cathepsin $\mathrm{D}$ genes with meat quality traits in double-muscled Piemontese cattle. Anim. Gen., 44: 193-196.

Ribeca C., B onfatti V., Cec chinat o A., A lbera A., Gallo L., Carnier P. (2014). Effect of polymorphisms in candidate genes on carcass and meat quality traits in double muscled Piemontese cattle. Meat Sci., 96: 1376-1383.

Sarti F.M., Lasagna E., Ceccobelli S., Di Lorenzo P., Filipini F., Sbarra F., G i o n te 11 a A. (2014). Influence of single nucleotide polymorphism in myostatin and myogenic factor 5 muscle growth-related genes on the performance trait of Marchigiana beef cattle. J. Anim. Sci., 92: 3804-3810.

Sellick G.S., Pitchford W.S., Morris C.A., Cullen N.G., Crawford A.M., Raads m a H.W., B ot te m a C.D. (2007). Effect of myostatin F94L on carcass yield in cattle. Anim. Gen., 38: 440-446.

Sevane N., Armstrong E., Cortés O., Wiener P., Pong Wong R., Dunner S., the GemQual Consortium. (2013). Association of bovine meat quality traits with genes included in the PPARG and PPARGC1A networks. Meat Sci., 94: 328-335.

S helt on G.D., Eng v a 11 E. (2007). Gross muscle hypertrophy in whippet dogs is caused by a mutation in the myostatin gene. Neuromuscul. Disord., 17: 721-722.

Shi M., Ga o X., Ren H., Yuan Z., Wu H., Li J., Zhang L., Ga o H., Li J., Xu S. (2011). Association analysis of CAPN1 gene variants with carcass and meat quality traits in Chinese native cattle. Afr. J. Biotechnol., 10: 17367-17371.

S i e ge 1 P.M., Mas s a gué J. (2003). Cytostatic and apoptotic actions of TGF- $\beta$ in homeostasis and cancer. Nat. Rev. Cancer., 3: 807-821.

S ingh U., D eb R., A lye thodi R.R., A lex R., Kumar S., Chakraborty S., Dhama K., $\mathrm{S}$ h arm a A. (2014). Molecular markers and their applications in cattle genetic research: A review. Biomark. Genom. Med., 6: 49-58.

S pill e r M.P., K a m ba du r R., J e a n plong F., Th o m a s M., M a rty n J.K., B a s s J.J., Shar $\mathrm{m}$ a M. (2002). The myostatin gene is a downstream target gene of basic helix-loop-helix transcription factor MyoD. Mol. Cell. Biol., 22: 7066-7082.

Tait R.G.J.R., Shackelford S.D., Whe ele r T.L., King D.A., K e ele J.W., Cas as E., $\mathrm{S} \mathrm{m}$ i th T.P.L., B e n n e $\mathrm{t} \mathrm{t}$ G.L. (2014). CAPN1, CAST, and DGAT1 genetic effects on preweaning performance, carcass quality traits, and residual variance of tenderness in a beef cattle population selected for haplotype and allele equalization. J. Anim. Sci., 92: 5382-5393.

Tu P.A., Shiau J.W., D ing S.T., L in E.C., Wu M.C., Wang P.H. (2012). The association of genetic variations in the promoter region of myostatin gene with growth traits in Duroc pigs. Anim. Biotechnol., 23: 291-298.

Undarmaa B., Munkhtogtokh B., Davaakhuu L., Sergelen B., Nyamsuren B., S o d n o m L. (2016). Sequencing analysis of myostatin gene (MSTN) for meat cattle in Mongolia. JAST A, 6: 429-434. 
W ęglarz A. (2011). Effect of pre-slaughter housing of different cattle categories on beef quality. Anim. Sci. Pap. Rep., 29: 43-52.

Wiener P., Woolliams J.A., Frank-Lawale A., Ryan M., Richardson R.I., Nut e G.R., Wo od J.D., Ho m er D., W ill i a m s J.L. (2009). The effects of a mutation in the myostatin gene on meat and carcass quality. Meat Sci., 83: 127-134.

www.ncbi.nlm.nih.gov/gene/?term=bos\%20taurus\%20capn2

X in J., Zh ang L., Li Z., Li u X., J in H., Yan C. (2011). Association of polymorphisms in the calpain I gene with meat quality traits in Yanbian yellow cattle of China. Asian-Australas. J. Anim. Sci., 24: 9-16.

Z ha ng R.F., Che n H., L e i C.Z., Zh ang C.L., L a n X.Y., Z h ang Y.D., Z h a n g H.J., B a o B., $\mathrm{N}$ i u H., W a n g X.Z. (2007). Association between polymorphisms of MSTN and MYF5 genes and growth traits in three Chinese cattle breeds. Asian-Australas. J. Anim. Sci., 20: 1798-1804.

Received: 25 III 2019

Accepted: 18 V 2020 